\title{
Fen Bilgisi Öğretmen Adaylarının Mikroskop Konusuna Yönelik Kavramları Öğrenmelerinin Geliştirilmesi ${ }^{1}$
}

DOI: $10.26466 /$ opus.647849

\author{
Fulya Zorlu* - Yusuf Zorlu ** \\ * Dr. Öğr. Üyesi, Zonguldak Bülent Ecevit Üniversitesi, Ereğli Eğitim Fakültesi \\ E-Posta: fulya.zorlu@beun.edu.tr \\ ORCID: 0000-0001-8167-0839 \\ ** Dr. Öğr. Üyesi, Kütahya Dumlupınar Üniversitesi, Eğitim Fakültesi \\ E-Posta: yusuf.zorlu@dpu.edu.tr \\ ORCID: $\underline{0000-0002-4203-0908}$
}

Öz

Çalışmanın amacı, fen bilgisi öğretmen adaylarının mikroskop konusuna yönelik kavramları öğrenmelerinin laboratuvar uygulamaları ve kavram ağları yoluyla geliştirilmesidir. Araştırmada eylem araştırması yöntemi kullanılmıştır. Araştırmaya bir devlet üniversitesinin eğitim fakültesinin fen bilgisi öğretmenliği bölümünde Genel Biyoloji Laboratuvarı-1 dersini alan 42 fen bilgisi öğretmen adayı katılmıştır. Çalışma kapsamında, ilk hafta kavram ağı ve özellikleri hakkında bilgiler verilerek örnekleri incelenmiştir. Sonraki iki hafta belirlenen deneyler fen bilgisi öğretmen adayları tarafından laboratuvar ortamında yapılmıştır. Dördüncü hafta mikroskop konusunda yer alan kavramlara yönelik olarak kavram ağlar hazırlamaları istenmiştir. Fen bilgisi öğretmen adayları tarafindan hazırlanmış olan 42 kavram ağı veri toplama aracı olarak kullanılmıştır. Kavram ağlarını değerlendirilmek için rubrik kullanılmıştır. Laboratuvar uygulamalarıla ve kavram ağlarıyla yapılan uygulamanın fen bilgisi öğretmen adaylarının mikroskop konusu ile ilgili anahtar kavram ve grupları kısmen öğrenmelerini sağladığı, kavram ağı oluşturmada yaşanan zorlukları da kısmen giderdiği tespit edilmiştir. Ayrıca önceden bildikleri kavramları ve uygulama esnasında mikroskop konusu ile ilgili anahtar kavramlar dışında kalan kavramları öğrenmelerini geliştirmiştir.

Anahtar Kelimeler: Eylem araştırması, fen eğitimi, kavram ağı, laboratuvar uygulamaları, mikroskop.

\footnotetext{
${ }^{1}$ Bu çalışma, 14. Uluslararası Eğitim Yönetimi Kongresi'nde sözlü bildiri olarak sunulmuştur
} 


\title{
Improving Learning Preservice Science Teachers' Concepts of Microscope Subject
}

\begin{abstract}
The aim of this study is to improve the preservice science teachers' learning about microscope concepts through laboratory applications and semantic mappings. Action research method was used in the study. 42 preservice science teachers taking General Biology Laboratory-1 course in science teaching department of faculty of education of a public university participated in the study. Within the scope of the study, first week the semantic mappings and its features were given and examples were examined. The experiments determined in the next two weeks were conducted by the preservice science teachers in the laboratory. In the fourth week, they were asked to prepare semantic mappings for the concepts of microscope. 42 semantic mappings prepared by preservice science teachers were used as dat a collection tools. Rubrics were used to evaluate semantic mappings. It has been determined that the applied made with laboratory applications and semantic mappings enables preservice science teachers to learn key concepts and groups related to the microscope subject and partially eliminates the difficulties in forming a semantic mapping. In addition, they learned the concepts they knew before and other concepts that were not relevant to the microscope subject during the application.
\end{abstract}

Keywords: Action research, laboratory applications, microscope, science education, semantic mapping. 


\section{Giriş}

İnsanlar yaşamlarını anlamlandırmak ve çevreleriyle uyum sağlamak için öğrenme ihtiyacı duyarlar. Bu ihtiyaçların giderebilmek adına çocukluktan başlayarak kavramları öğrenir, sınıflandırır ve aralarındaki ilişkileri bulurlar (Gödek, Polat ve Kaya, 2018). Novak ve Gowin (1984)'e göre kavramlar; nesneler veya olaylarda algilanan bir etiket, işaret veya sembolle gösterilen düzenliliklerdir. İsimleri, özellikleri ve ilişkili örnekleri olan kavramlar; hayatın içinde gerçekleşen olayları ve doğayı sistemli bir şekilde inceleyen fen bilimleri için de çok önemli bir yere sahiptir (İnel-Ekici, 2014; Kaptan, 1998). Çünkü birbiriyle ilişkili ve karmaşık yapıda birçok kavramı barındıran fen bilimlerinde etkili öğrenme için öğrenciler tarafından kavramların doğru bir şekilde bilinmesi ve kullanılması gerekmektedir. Dolayısıyla fen kavramlarının öğretim sürecine dikkat edilmelidir.

Fen kavramlarının öğretim süreci farklı faktörlerden olumlu ya da olumsuz etkilenebilmektedir. İnel-Ekici (2014)'e göre kavram öğretiminde öğrencilerin temel bilgi eksiklerinin ya da yanlış kavramsallaştırmalarının olması bu süreci olumsuz yönde etkileyebilmektedir. Özellikle öğrenciler tarafından gözle görülmesi zor olan maddelerin ya da canlılara ait özelliklerin bilinmesi daha zordur. Öğrencilerin bu tür konuları etkili öğrenmelerini sağlamak amaciyla fen laboratuvarlarında mikroskoplardan yararlanılmaktadır. Fen eğitiminde ilk yıllardan itibaren derslerde öğrenmeyi sağlayan bir araç olan mikroskop, bir mercek düzeneği yardımıyla mikroorganizmaları görmeyi ve karmaşık vücut sistemini hücre seviyesinde incelemeyi mümkün kılar (Benzer ve Demir, 2014; Kara, 2018; Türk Dil Kurumu [TDK], 2019). Mikroskoplar, ögrencilere gözle göremedikleri mikron (mikrometre) boyutundaki dünyayı gözleme firsatı sunarak öğrenme ve kavramsal düzeyde anlama kolaylığ sağlamaktadır (Benzer ve Demir, 2014; Kara, 2018; Nelson, Clarke ve Dede, 2010).

Öğrenilmesinin ve kavramsal düzeyde anlaşılmasının zorluğu düşünülerek fen konularındaki ilgili kavramların ne düzeyde öğrenildiği ortaya konmalıdır (Gödek, Polat ve Kaya, 2018). Bu bağlamda fen öğretiminde kavram ağı uygulamalarından yararlanılabilir (McIntosh, 1995). Kavram ağı, kelimeleri ve fikirleri organize ederek ilişkileri ortaya koyan grafiksel bir sunum aracıdır (Schewel, 1989; Washington, 1988). Öğrencilerin hafıza süreçlerine, s1nıflandırma yeteneklerine ve öğrenilen materyali yansıtma yeteneklerine 
yardımcı olmanın görsel bir aracı olduğu için etkili bir değerlendirme tekniği de olabilir (Vaughan, Sumrall ve Rose, 1998). Kavram ağı uygulamaları öğrencilerin aktif katılımcılar olarak konuyla ilgilenmelerine (Heimlich ve Pittelman, 1986), öğrendikleri bilgileri gözden geçirmelerine, öğrendikleri kavramlar arasında ilişkiler kurarak sınıflandırmalar yapmalarına (Açıkgöz, 2009); düşünme becerilerini geliştirerek konuyu daha iyi anlamalarına (Tuna, 2013); öğretmenlerin öğrencilerinin bilişsel ve duyuşsal düşünce durumlarını değerlendirmelerine (Avery, Baker ve Gross, 1996) ve sürecin niteliği hakkında bilgi sahibi olmalarına olanak sağlar (McCoy, Maag ve Rucker, 1989).

İlgili alanyazın incelendiğinde kavram ağı uygulamalarının etkilerini belirleme (Badr ve Abu-Ayyash, 2019; Bölükbaş ve Özdemir, 2009; Dilek ve Yürük, 2013; Lipson, 1995; Sadeghi ve Taghavi, 2014; Saragih, 2019; Tuna, 2013), kavram yanılgılarını belirleme (Demir ve Sezek, 2012; Yılmaz ve Çiviler, 2012) ve farklı bir yöntemin etkisini ölçme-değerlendirme (Peşman ve Bülbül, 2012; Vaughan, Sumrall ve Rose, 1998) amaçları doğrultusunda gerçekleştirildiği görülmektedir. Bu bağlamda kavram ağı uygulamalarının eğitim alanında kullanımına yönelik çalışmaların yapılmış olduğu ve bu çalışmaların sonuçlarının farklı katkılar sağladığı görülmektedir. Ancak laboratuvar uygulamaları ve kavram ağları yoluyla kavram öğreniminin geliştirilmesine yönelik bir çalışmaya rastlanmamıştır. Ayrıca mikroskobun fen alanlarında kullanımı ve önemi nedeniyle, fen öğrencilerinin mikroskopları tanımaları ve bunları kullanabilmeleri için öncelikle fen bilgisi öğretmen adaylarının ilgili kavramları tam ve doğru bir biçimde öğrenmiş olmaları gerekmektedir (Kara, 2018). Bu doğrultuda gerçekleştirilen çalışmanın amacı, fen bilgisi öğretmen adaylarının mikroskop konusuna yönelik kavramları öğrenmelerinin laboratuvar uygulamaları ve kavram ağları yoluyla geliştirilmesidir. Araştırma kapsamında aşağıdaki araştırma sorusuna yanıt aranmıştır.

"Fen bilgisi öğretmen adaylarının mikroskop konusuna yönelik kavramları öğrenmelerini laboratuvar uygulamaları ve kavram ağları geliştirmekte midir?

\section{Yöntem}

Eylem araştırması, eylemlerin ve öğretimin niteliğini anlamak ve iyileştirmek için gerçek sınıf veya okul durumunu çalışma süreci olarak tanımlanabilir (Hensen, 1996; McTaggart, 1997; Schmuck, 1997'den aktaran Johnson, 2015). 
Araştırmada eylem araştırması yöntemi kullanılmıştır. Laboratuvar uygulamalarında en çok kullanılan cihazlardan biri mikroskoptur (Basey, Mendelow ve Ramos, 2000; Dökme, Doğan ve Yllmaz, 2010; Ekici, 2016; Green ve Smith III, 2005). İlgili literatür incelediğinde fen eğitiminde mikroskop ile ilgili kavramların ve kullanımının tam olarak bilinmemesine yönelik sorunlar olduğu tespit edilmiştir (Harman, 2012; Uzel, Diken, Yılmaz ve Gül, 2011). Ayrıca fen bilgisi öğretmenlerinin fen bilimleri derslerinde mikroskop kullanmadıkları veya kullanamadıkları görülmektedir (Benzer ve Demir, 2014; Erişti ve Tunca, 2012). Bu bağlamda fen bilimleri öğretmenlerinin lisans programlarında öğretmen adayı iken mikroskop ile ilgili kavramları bilmelerine ve kullanmalarına yönelik sorunlar dikkate alınarak eylemlerin ve öğretimin niteliğini artırmak amacıyla bu araştırma gerçekleştirilmiştir.

\section{Çalışma Grubu}

Araştırmada amaçlı örnekleme yöntemi kullanılmıştır. Amaçlı örnekleme yöntemi; araştırmacının keşfetmek, anlamak, iç görü kazanmak istediği ve çoğu şeyin öğrenileceği bir örneklem seçiminin zorunlu olduğu varsayımına dayanmaktadır (Merriam, 2013). Amaç, uygulama yapılan öğrencilerin Genel Biyoloji Laboratuvarı-1 dersini alan fen bilgisi öğretmen adayları olmalarıdır. Bu kasıt doğrultusunda araştırmaya bir devlet üniversitesinin eğitim fakültesinin ikinci sınıfında öğrenim gören 42 fen bilgisi öğretmen adayı katılmıştır. Araştırmaya katılan fen bilgisi öğretmen adaylarının 6's1 erkek ve 36'sı kadındir.

\section{Eylem Planı}

Çalışma kapsamında fen bilgisi öğretmen adaylarıyla dört hafta (16 saat) süren uygulamalar yapılmıştır.

1. İlk hafta (4 saat) fen bilgisi öğretmen adaylarına kavram ağı ve özellikleri hakkında bilgiler verilerek örnekleri incelenmiştir. Ayrıca, fen bilgisi öğretmen adayları ile beraber mikroskobu öğrenme ve kullanmaya yönelik deneyler belirlenmiştir.

2. Sonraki iki hafta (8 saat) belirlenen deneyler öğretmen adayları tarafından laboratuvar ortamında yapılmıştır. Fen bilgisi öğretmen adaylarının kararlaştırdıkları deneylere ait bilgiler aşağıda verilmiştir. 
a. Mikroskobun yapısı ve özellikleri incelenerek, mikroskopta incelemenin nasıl yapıldığı uygulamalı olarak gösterildi. Bu aşamada ilk olarak mikroskop kısımları incelenmiştir. Daha sonra mikroskobun kullanımına yönelik bilgiler verilerek küçük bir kâğıda çizilen harfler (e ve F harfleri) ile uygulamalar yapılmıştır. Yapılan diğer bir uygulama ise bitki ve hayvan hücrelerinin karşılaştırılması deneyidir. İncelenen objeler olarak bitki hücresi için soğan zarı ve hayvan hücresi için dil epitel hücresi kullanılmıştır. Uygulamalar yapılırken mikroskobun her bir parçasına ait özelliklerin bizzat fen bilgisi öğretmen adayları tarafından uygulamalı bir şekilde incelenmesi sağlanmıştır.

3. Dördüncü hafta (4 saat) fen bilgisi öğretmen adaylarından mikroskop cihazında yer alan kavramlara yönelik olarak kavram ağları hazırlamaları istenmiştir.

\section{Veri Toplama Yöntemi, Aracı ve Analizi}

Araştırmada veri toplama yöntemi olarak eylem araştırmasının incelemeye dayalı veri toplama yöntemi kullanılmıştır. İncelemeye dayalı veri toplama yönteminde veri toplama aracı olarak ürünler kullanılmıştır. Bu araştırmada ürünler, fen bilgisi öğretmen adayları tarafından hazırlanmış olan 42 kavram ağından oluşmuştur.

Hazırlanan kavram ağlarını incelemek üzere araştırmacılar tarafından kavram ağının genel özellikleri dikkate alınarak rubrik oluşturulmuştur. Rubrik oluşturma aşamalan:

1. İlgili alanyazın incelemesi yapılarak mikroskop konusuna ait anahtar gruplar ve anahtar kavramlar belirlenmiştir (Arslan, Bahar ve Özel, 2011; Efe, 2000; Elçin, Erkoç, Atik, Selvi, Sarıkaya ve Öztekin, 2010). İlgili literatür incelendikten sonra beş anahtar grup ve 32 anahtar kavram belirlenmiştir.

- Anahtar gruplar: Optik Kısım, Mekanik Kısım, Mikroskop Çeşitleri, Kullanım Şekli/Alanları ve Mikroskop Kısımları/Bölümleri

- Anahtar Kavramlar: Optik Kısım, Mekanik Kısım, Mikroskop Ayağı/ Alt Kaide, Mikroskop Kolu/ Gövde Kolu, Mikroskop Tablası/Nesne Tablası, Maşalar/Klipsler, Çukur ve Tümsek Ayna, Diyafram, Kondansatör, Mikroskop Tüpü, Makro (Kaba) Ayar, Mikro (İnce) Ayar, Döner Levha (Revolver), Oküler, Objektif, Büyütme Gücü, Mikron/Mikrometre, Işık Mikroskobu, Geçirmeli Elektron Mikroskobu, Taramalı Elektron Mikroskobu, 
Streo Mikroskop/Bioküler, Karanlık Alan Mikroskobu, Floresan Mikroskobu, Faz/Konstrat Mikroskobu, İnterferens Mikroskobu, Metalurji Mikroskobu, X-Işını Mikroskobu, Atomik Kuvvet Mikroskobu, Saha Emisyon Mikroskobu, Elektron Mikroskobu, Işık Kaynağı, Kalibrasyon Faktörü, Piksel.

Tablo 1. Kavram ă̆ı inceleme rubriği

\begin{tabular}{llllll}
\hline \multirow{2}{*}{ Temalar } & \multicolumn{5}{c}{ Puan/Kodlar } \\
\cline { 2 - 6 } Anahtar Kavramlar & $\mathbf{5}$ puan & 4 puan & 3 puan & 2 puan & 1 puan \\
\hline Anahtar Gruplar & $32-25$ & $24-19$ & $18-13$ & $12-7$ & $6-1$ \\
kavram & kavram & kavram & kavram & kavram \\
\hline $\begin{array}{l}\text { İçerdiği Anahtar Kavramlara Göre } \\
\text { Grupların Uygunluğu }\end{array}$ & 5 grup & 4 grup & 3 grup & 2 grup & 1 grup \\
\hline $\begin{array}{l}\text { Anahtar Kavram } \\
\text { Dişındaki Kavramlar }\end{array}$ & $\ldots-21$ & $20-16$ & $15-11$ & $10-6$ & $5-1$ \\
\hline $\begin{array}{l}\text { Kavram Ağ Oluşturmada Gruplardan } \\
\text { Önemli Olanları Vurgulama }\end{array}$ & kavram & kavram & kavram & kavram & kavram \\
\hline
\end{tabular}

2. Anahtar grup ve kavramlar belirlendikten sonra kavram ağlarının özellikleri dikkate alınarak beş madde ve beşli derecelendirmeli rubrik hazırlanmıştır (Tablo 1). Alanında uzman iki öğretim üyesi tarafından incelenerek son hali verilmiştir. Rubrik her bir madde 5 puan üzerinden toplam 25 puandan oluşmaktadır. Rubrikte üç maddede kavramların sayısına göre puanlama yapılmışken, diğer iki maddede kavramların yüzde değerine göre puanlama yapılmıştır.

Oluşturulan rubrik ile fen bilgisi öğretmen adaylarının hazırlamış oldukları kavram ağları analiz edilmiştir. Hazırlanan kavram ağları iki öğretim üyesi tarafından betimsel analiz yöntemiyle incelenmiştir. Rubrikte yer alan maddeler tema olarak, puan değeri de kod olarak kullanılmıştır. Analizden elden edilen veriler frekans ve yüzde olarak verilmiştir.

\section{Bulgular}

Fen bilgisi öğretmen adaylarının mikroskop konusunda hazırlamış oldukları kavram ağlarındaki grupların betimsel analizine ait bulgular Tablo 2'de verilmiştir. 
Fen Bilgisi Öğretmen Adaylarının Mikroskop Konusuna Yönelik Kavramları Öğrenmelerinin Geliştirilmesi

Tablo 2. Fen bilgisi öğretmen adaylarının mikroskop konusunda hazırlamış olduklar kavram ağlarnın betimsel analiz sonuçlarn

\begin{tabular}{|c|c|c|c|c|}
\hline Temalar & Kodlar & Puan & $\mathbf{f}$ & $\%$ \\
\hline \multirow[t]{6}{*}{ Anahtar Kavramlar } & 32-25 anahtar kavram & 5 & 0 & 0 \\
\hline & 24-19 anahtar kavram & 4 & 7 & 16.7 \\
\hline & 18-13 anahtar kavram & 3 & 13 & 31.0 \\
\hline & 12-7 anahtar kavram & 2 & 18 & 42.9 \\
\hline & 6-1 anahtar kavram & 1 & 4 & 9.5 \\
\hline & Toplam & & 42 & 100 \\
\hline \multirow[t]{6}{*}{ Anahtar Gruplar } & 5 anahtar grup & 5 & 0 & 0 \\
\hline & 4 anahtar grup & 4 & 7 & 16.7 \\
\hline & 3 anahtar grup & 3 & 9 & 21.4 \\
\hline & 2 anahtar grup & 2 & 10 & 23.8 \\
\hline & 1 anahtar grup & 1 & 16 & 38.1 \\
\hline & Toplam & & 42 & 100 \\
\hline İçerdiği Anahtar Kavramlara Göre Grupların & $\%$ 100-81 & 5 & 19 & 45.2 \\
\hline \multirow[t]{5}{*}{ Uygunluğu } & $\% 80-61$ & 4 & 13 & 31.0 \\
\hline & $\% 60-41$ & 3 & 5 & 11.9 \\
\hline & $\% 40-21$ & 2 & 3 & 7.1 \\
\hline & $\% 20-1$ & 1 & 2 & 4.8 \\
\hline & Toplam & & 42 & 100 \\
\hline \multirow[t]{6}{*}{ Anahtar Kavram Dışındaki Kavramlar } & $\ldots-21$ kavram & 5 & 12 & 28.6 \\
\hline & 20-16 kavram & 4 & 5 & 11.9 \\
\hline & 15-11 kavram & 3 & 7 & 16.7 \\
\hline & 10-6 kavram & 2 & 14 & 33.3 \\
\hline & 5-1 kavram & 1 & 4 & 9.5 \\
\hline & Toplam & & 42 & 100 \\
\hline Kavram Ağı Oluşturmada Gruplardan & $\% 100-81$ & 5 & 0 & 0 \\
\hline \multirow[t]{5}{*}{ Önemli Olanları Vurgulama } & $\% 80-61$ & 4 & 1 & 2.4 \\
\hline & $\% 60-41$ & 3 & 1 & 2.4 \\
\hline & $\% 40-21$ & 2 & 7 & 16.7 \\
\hline & $\% 20-1$ & 1 & 33 & 78.6 \\
\hline & Toplam & & 42 & 100 \\
\hline
\end{tabular}

Fen bilgisi öğretmen adaylarının mikroskop konusunda hazırlamış oldukları kavram ağlarının rubriğe göre puanlanmasından elde edilen verilere ait bulgular Grafik 1'de verilmiştir. 


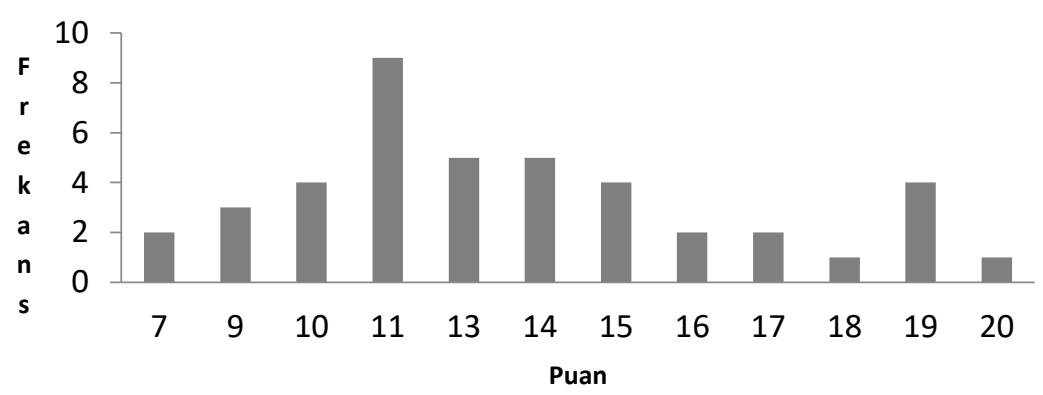

Grafik 1. Kavram Ağlarnın Rubriğe Göre Puanlanmasından Elde Edilen Verilerin Dağılımı

Grafik 1 incelendiğinde fen bilgisi öğretmen adaylarının hazırlamış oldukları kavram ağlarından en çok 9 kavram ağı ile 11 puan aldıkları ve en az 1 kavram ağı ile 18 ve 20 puan aldıkları görülmektedir. Fen bilgisi öğretmen adaylarının hazırlamış oldukları kavram ağlarından en yüksek puanın 20 (1 kavram ağı) ve en düşük puanın 7 ( 2 kavram ağı) olduğu görülmektedir. Fen bilgisi öğretmen adaylarının hazırlamış oldukları kavram ağlarından aldıkları puanlar çoğunlukla (27 kavram ağı) 10-15 puan aralığındadır. Ayrıca fen bilgisi öğretmen adaylarının hazırlamış oldukları kavram ağlarında 21-25 puan aralığında kavram ağının olmadığı görülmektedir.

\section{Tartışma ve Sonuç}

Fen bilgisi öğretmen adaylarının mikroskop konusuna yönelik kavramları öğrenmelerinin laboratuvar uygulamaları ve kavram ağları yoluyla geliştirilmesinin amaçlandığı çalışmaya ait bulgulardan elde edilen sonuçlar ve sonuçların nedenleri alanyazın ile tartışılarak bu bölümde verilmiştir.

Araştırma kapsamında belirlenen 32 anahtar kavrama göre "Anahtar Kavramlar" temasında fen bilgisi öğretmen adaylarının hazırladıkları kavram ağlarında 7-18 anahtar kavrama yer verdikleri belirlenmiştir. Ayrıca 19-24 anahtar kavrama yer verilen kavram ağlarının olduğu da görülmektedir. Araştırma kapsaminda belirlenen 5 anahtar gruptan "Anahtar Gruplar" temasında fen bilgisi öğretmen adaylarının hazırladıkları kavram ağlarının çoğunda 1-3 arasında anahtar gruba yer verdikleri tespit edilmiştir. Ayrıca 4 
anahtar gruba yer veren fen bilgisi öğretmen adaylarının olduğu da belirlenmiştir. Elde edilen bulgulara göre, fen bilgisi öğretmen adaylarının mikroskop konusu ile ilgili anahtar kavramların ve grupların bir kısmını öğrendikleri söylenebilir. Bu öğrenmelerin gerçekleşmesinde öğretmen adaylarının laboratuvar ortamında yaptıkları deneylerin ve kavram ağı hazırlarken yaptıkları araştırmaların etkili olduğu söylenebilir. İlgili alanyazın incelendiğinde kavram ağlarının ve deneylerin kavram öğretiminde etkili olduğu sonuçlarıyla bu çalışmanın sonuçlarının paralellik gösterdiği tespit edilmiştir (Dilek ve Yürük, 2013; Fitzgerald, Elmore, Kung ve Stennen, 2017; Gödek, Polat ve Kaya, 2018; Patrizi, Ice ve Burgess, 2013; Reza ve Azizah, 2019).

Deney ve etkinlik yapılarak gerçekleştirilen uygulamalı çalışmalar soyut ifadelerin (kavramların) öğrenilmesinde ve yaparak yaşayarak öğrenmede önemlidir (Çepni ve Ayvacı, 2006; Kesercioğlu, Balım, Öztürk ve Çavaş, 2004; Nelson, Clarke ve Dede, 2010; Yazıcı ve Kurt, 2018). Ketelhut, Nelson, Clarke ve Dede (2010) araştırmalarında öğrencilerin mikroskopla deney yapmaları ile hipotez ve deneyleri kurgulayarak kendini bir bilim insanı gibi hissedebileceğini belirtmektedirler. İlgili alanyazında fen bilgisi öğretmen adaylarının mikroskop konusunda çok az kavram bildikleri ve bildikleri kavramların eksik veya hatalı olduğu sonuçları olan çalışmaların olduğu görülmektedir (Harman, 2012; Uzel ve diğ., 2011). Araştırmada kullanılan rubrikten en yüksek 25 puandır. Fen bilgisi öğretmen adaylarının hazırlamış oldukları kavram ağlarından sadece bir tanesinin 20 puan ve dört tanesinin 19 puan aldığı görülmektedir. Bununla birlikte hazırlanan kavram ağlarının çoğunun 10-15 puan aralığında olduğu görülmektedir. "Kavram A $\breve{g ̆}_{l}$ Oluşturmada Gruplardan Önemli Olanları Vurgulama" temasında kavram ağı oluşturmada gruplardan önemli olanı vurgulamada fen bilgisi öğretmen adaylarının çoğunun \%20-1 yüzde seviyesinde olduğu görülmektedir. Elde edilen bu bulguya göre laboratuvar uygulamalarıyla ve kavram ağlarıyla yapılan uygulamanın fen bilgisi öğretmen adaylarının kavram ağı oluşturmada zorluklar yaşadıkları ve bu zorlukların tam olarak giderilemediği görülmektedir. Bu araştırmada fen bilgisi öğretmen adaylarının hazırladıkları kavram ağlarından mikroskop konusunda istenen düzeyde olmadıkları ve düzeylerinin geliştirilmesi gerektiği görülmektedir. Bunun birçok nedeni olabilir. Nedenlerden biri olarak araştırmanın 16 ders saati kapsamında yapılması ve bu saatin az olması gösterilebilir. Bu çalışmada da görülmektedir ki bu tarz uygulamaların uzun süreli ol- 
ması ve mümkün mertebe öğretmen adaylarının mikroskobu kullanarak öğrenmelerinin sağlanması gerekmektedir. Zorlu (2016) ve Zorlu ve Sezek (2019) çalışmalarında uzun süreli uygulama yaptıkları ve uygulama sonucunda yöntemin etkililiğini daha iyi bir şekilde tespit ettiklerini ifade etmişlerdir. Uzun süren veya arayla birden fazla uygulama yapılan öğrencilerin dersleri daha iyi öğrendikleri görülmektedir (Zorlu, 2016).

"İçerdiği Anahtar Kavramlara Göre Gruplarm Uygunluğu" temasindan fen bilgisi öğretmen adaylarının yaptıkları kavram ağlarının çoğunda gruplarda yer alan kavramların \%61-100'ü grup ismi ile uygundur. Elde edilen bulgulara göre fen bilgisi öğretmen adaylarının kavram ağı hazırlarken ilgili kavramları kullanarak uygun gruplandırmalar yaptıkları söylenebilir. "Anahtar Kavram Dışındaki Kavramlar" temasında fen bilgisi öğretmen adaylarının hazırladıkları kavram ağlarında anahtar kavram dışında kullandıkları kavramlar incelendiğinde en çok 6-10 tane ve 21-üzeri kavrama yer verdikleri görülmektedir. Fen bilgisi öğretmen adayları hazırlamış oldukları 12 kavram ağında 11-20 arasında anahtar kavram kullanmışlardır. Elde edilen bulgulara göre laboratuvar uygulamalarıyla ve kavram ağlarıyla yapılan uygulamanın fen bilgisi öğretmen adaylarının önceden bildikleri kavramları ve uygulama esnasında mikroskop konusu ile ilgili anahtar kavramlar dışında kalan kavramları öğrendikleri de söylenebilir. Yeni bilgilerin öğrenilmesi önceki bilgilerin tekrar edilmesini ve canlanmasını sağlar (Güneş, 2007; Köksal ve Atalay, 2016; Onan, 2012). Bellekte büyük bilgi örüntülerini temsil edici yapılara ihtiyaç vardır. Organize edilmiş bilgi örüntülerini temsil eden veri yapılarına kavramsal yapı, çerçeve, şema denir (Senemoğlu, 2018). Fen bilgisi öğretmen adaylarının hazırladıkları kavram ağları sayesinde mikroskop konusundaki kavramlara ait şemalar oluşturdukları söylenebilir. Şema Kuramına göre yeni bilgi iyi gelişmiş, uygun bir şema içerisine yerleştirildiği takdirde hatırlanması daha kolay olur (Senemoğlu, 2018). Bilgiler birden çok kanal aracılığıyla öğrencilere ulaştırılmalıdır. Öğretim sürecinde sadece işitsel değil, görsel kanallar da kullanılmalıdır. Bu ve benzeri uygulamalar, öğrencilerin doğru şemaları oluşturmalarına yardımcı olacaktır. Bu çerçevede oluşturulmuş doğru şemalar, sonraki öğrenmelerde oluşturulacak şemalar üzerinde olumlu bir etki yaratacaktır (Onan, 2012).

Araştırmadan elde edilen bulgularda fen bilgisi öğretmen adaylarının anahtar kavram dışında konu ile ilişkili birçok kavrama da kavram ağlarında 
yer verdikleri belirlenmiştir. Elde edilen bu sonuca göre laboratuvar uygulamalarıyla ve kavram ağlarıyla yapılan uygulamanın fen bilgisi öğretmen adaylarının deney uygulamalarının ve kavram ağı hazırlamalarının mikroskop konusuna yönelik araştırmalar yapmalarını sağladığı söylenebilir. Fen bilgisi eğitiminde deney uygulamalarıyla verimliliği arttırabilmek için önceden sahip olunan bilgilerin ortaya konularak mevcut bilgilerin etkinleştirilip yeni bilgilerin anlamlı parçalar içerisinde düzenlenmeleri önemlidir (Bruning, Schraw ve Norby, 2010). Özellikle fen derslerinde yapılan deneyler ve etkinlikler bilimsel gerçekleri öğrenmede, daha uzun süre akılda tutmada ve öğrencilerin fen bilimlerine karşı ilgi ve tutumlarını olumlu yönde geliştirmede etkilidir (Chiapetta ve Koballa, 2001; Hofstein ve Lunetta, 1980; Kapuscinski, 1981; Panichas, 2006; Switzer ve Shriner, 2000; Taşkın, 2008). Fen derslerinde aktif öğrenmeyi sağlamak amacıyla deneylerin yapılması konuları öğrenmede yararlar sağlamakta ve araştırmaya teşvik etmektedir (Demir, 2017; Demirçalı, 2016; Güldal, 2018; Halloun, 2006, 2007; Zorlu, 2016).

\section{Öneriler}

Elde edilen sonuçlar doğrultusunda fen eğitiminde kavram öğretimine yardımcı olan kavram ağlarının kullanılması ve yaygınlaştırılması önerilmektedir. Çünkü araştırmaya katılan fen bilgisi öğretmen adaylarının kavram ağlarını hazırlamada zorlandıkları ve istenilen düzeyde kavram ağı oluşturamadıkları tespit edilmiştir. Ayrıca fen öğrenme ortamlarında kavram ağlarının yanı sıra kavramları gruplandırırken önemli grupları vurgulayacak çeşitli etkinliklere de yer verilebilir. Fen eğitiminde aktif öğrenmenin sağlanması ve temel bilgilerin uygulanarak öğrenilmesi için deneylerin yapılması ve bu deneylerde araç-gereçlerin doğru bir şekilde kullanılması gerekmektedir. Fen eğitiminde mikroskop gibi teknik bilgi gerektiren araçların doğru bir biçimde kullanılması ve gerekli bilgilerin öğrenilmesi için kısa süreli uygulamalar yerine uzun süreli veya farklı zamanlarda dönemsel uygulamaların yapılması önerilmektedir. Özellikle fen bilgisi öğretmen adaylarının araç-gereçleri daha iyi öğrenebilecekleri uygulamalara laboratuvar derslerinde yer verilmesi ile ileride daha verimli deneyler yapılacağı ve böylece öğrenmede niteliğin artacağ 1 düşünülmektedir. 


\title{
EXTENDED ABSTRACT
}

\section{Improving Learning Preservice Science Teachers' Concepts of Microscope Subject}

\author{
Fulya Zorlu - Yusuf Zorlu \\ Zonguldak Bülent Ecevit University, Kütahya Dumlupinar University,
}

The microscope, a tool that allows learning in lessons since the early years in science training, enables to see microorganisms with the help of a lens assembly and examine the complex body system at cell level (Benzer and Demir, 2014; Kara, 2018; Türk Dil Kurumu [TDK], 2019). Microscopes give students the opportunity to observe the micron (micrometer) world that they can't see, providing ease of learning and conceptual understanding (Benzer and Demir, 2014; Kara, 2018; Nelson, Clarke and Dede, 2010). It should be revealed the level of learning of the relevant concepts in science subjects should be revealed by considering the difficulty of learning and understanding at the conceptual level (Gödek, Polat ve Kaya, 2018). In this context, semantic mappings applications can be used in science teaching (McIntosh, 1995). When the relevant field is examined, it is seen that there are studies carried out for different purposes related to the semantic mappings (Badr and Abu-Ayyash, 2019; Bölükbaş and Özdemir, 2009; Demir and Sezek, 2012; Dilek and Yürük, 2013; Lipson, 1995; Peşman and Bülbül, 2012; Sadeghi and Taghavi, 2014; Saragih, 2019; Tuna, 2013; Vaughan, Sumrall and Rose, 1998; Yılmaz and Çiviler, 2012). However, no study has been found on the development of concept learning through laboratory applications and semantic mappings. In addition, because of the use and importance of microscopes in science fields, science students must first fully and accurately learn about the relevant concepts in order to recognize and use microscopes. The aim of this study is to improve the preservice science teachers' learning about microscope concepts through laboratory applications and semantic mappings.

Action research method was used in the study. When the relevant literature examined, it was determined that there were problems in science education that the concepts and use of microscopes were not fully known (Basey, Mendelow and Ramos, 2000; Harman, 2012; Uzel, Diken, Yılmaz and Gül, 
2011). In addition, it is seen that science teachers do not use or use a microscope in science courses (Benzer and Demir, 2014; Erişti and Tunca, 2012). In this context, this research was carried out in order to increase the nature of actions and teaching by taking into account the problems of science teachers knowing and using concepts related to the microscope while being a preservice science teacher in undergraduate programs. The sampling method was used for the purpose of the study. The aim is that the students who are applied are preservice science teachers who take the General Biology Laboratory- 1 course. 42 preservice science teachers taking General Biology Laboratory-1 course in science teaching department of faculty of education of a public university participated in the study. Within the scope of the study, first week the semantic mappings and its features were given and examples were examined. The experiments determined in the next two weeks were conducted by the preservice science teachers in the laboratory. In the fourth week, they were asked to prepare semantic mappings for the concepts of microscope. 42 semantic mappings prepared by preservice science teachers were used as data collection tools. Rubrics were used to evaluate semantic mappings.

According to the 32 key concepts determined within the scope of the research, it was determined that the preservice science teachers contained 7-18 key concepts in the semantic mappings prepared by the "Key Concepts" theme. In the theme of "Key Groups" from 5 key groups determined within the scope of the research, it was determined that preservice science teachers were among 1-3 key groups in most of the semantic mappings prepared by the preservice science teachers. The preservice science teachers prepared most of the semantic mappings are in the range of 10-15 points. In the theme of "Highlighting What Is Important from Groups in Creating a Concept Network", science is 20-1 percent of the majority of the preservice science teachers in the semantic mapping to highlight what is important from groups. $61-100 \%$ of the concepts in groups are suitable for group name in most of the concepts made by the preservice science teachers from the theme "Eligibility of Groups by Key Concepts". According to the findings, science can be said that the preservice science teachers make appropriate groupings using the relevant concepts when preparing a semantic mapping. When examining the concepts used outside the key concept in the theme of "Concepts Other than Key Concept", it is seen that there are up to 6-10 and 21-over grips in the concepts that preservice 
science teachers prepare. It has been determined that the applied made with laboratory applications and semantic mappings enables preservice science teachers to learn key concepts and groups related to the microscope subject and partially eliminates the difficulties in forming a semantic mapping. In addition, they learned the concepts they knew before and other concepts that were not relevant to the microscope subject during the application.

\section{Kaynakça / References}

Açıkgöz, K. Ü. (2009). Aktiföğrenme. İzmir: Biliş.

Arslan, O., Bahar, M. ve Özel, Ç. A. (2011). Genel biyoloji laboratuvar kılavuzu. Ankara: Palme.

Avery, P. G., Baker, J. ve Gross, S. H. (1996). Mapping learning at the secondary level. The Social Studies, 87(5), 217-223. doi:10.1080/00377996.1996.9958442

Badr, H. M. ve Abu-Ayyash, E. A. S. (2019). Semantic mapping or rote memorisation: Which strategy is more effective for students' acquisition and memorization of 12 vocabulary? Journal of Education and Learning, 8(3), 158-174.

Basey, J. M., Mendelow, T. N. ve Ramos, C. N. (2000). Current trends of community college lab curricula in biology: An analysis of inquiry, technology and content. Journal of Biological Education, 34(2), 80-86. doi: 10.1080/00219266.2000.9655690

Benzer, E. ve Demir S. (2014). Fen bilgisi öğretmen adaylarının mikroskop kullanım bilgilerinin incelenmesi. Mersin Üniversitesi Ĕ̆itim Fakültesi Dergisi, 10(3), 1-21.

Bölükbaş, F. ve Özdemir, E. (2009). Aktif öğrenmenin yazılı anlatım becerilerine etkisi. Hasan Ali Yücel Ĕğitim Fakültesi Dergisi, 12(2), 27-43.

Bruning, R. H., Schraw, G. J. ve Norby, M. M. (2010). Cognitive psychology and instruction (5. Baskı). USA: Pearson.

Çepni, S. ve Ayvacı, S. (2006). Kuramdan uygulamaya fen ve teknoloji öğretimi. Ankara: PegemA.

Chiappeta, E. L. ve T. R. Koballa (2001). Science instruction in the middle and secondary schools (7. baskı). USA: Prentice Hall.

Demir, A. (2017). Modellemeye dayalı etkinliklerin beşinci sınfföğrencilerinin heyelan konusundaki informal muhakemelerinin ve argümanlarınn gelişimine etkisi. Yayımlanmamış yüksek lisans tezi. Recep Tayyip Erdoğan Üniversitesi, Rize. 
Demirçalı, S. (2016). Modellemeye dayal fen öğretiminin öğrencilerin akademik başartlarna, bilimsel süreç becerilerine ve zihinsel model gelişimlerine etkisi: 7. simf güneş sistemi ve ötesi-uzay bilmecesi ünitesi örneği.Yayımlanmamış yüksek lisans tezi, Gazi Üniversitesi, Ankara.

Dilek, Y. ve Yürük, N. (2013). Using semantic mapping technique in vocabulary teaching at preintermediate level. Procedia-Social and Behavioral Sciences, 70, 1531-1544.

Dökme, İ., Doğan, A. ve Yılmaz, M. (2010). Fen öğretimi laboratuvar uygulamaları III. Ankara: Palme.

Efe, N. (2000). Genel biyoloji laboratuvarı. Erzurum: Bakanlar Media.

Ekici, G. (2016). Biyoloji öğretmeni adaylarının mikroskop kavramına ilişkin algilarının belirlenmesi: Bir metafor analizi çalışması. Ahi Evran Üniversitesi Kurşehir Ĕ̆itim Fakültesi Dergisi (KEFAD), 17(1), 615-636.

Elçin, A. E., Erkoç, F., Atik, A. D., Selvi, M., Sarıkaya, R. ve Öztekin, M. (2010). Biyoloji laboratuvarinin temelleri. Ankara: Palme.

Erişti, B. ve Tunca, N. (2012). Opinions of primary school science and technology teachers about developing students' affective competence. Turkish Online Journal of Qualitative Inquiry, 3(1), 36-54.

Fitzgerald, W. J., Elmore, J., Kung, M. ve Stennen, A. J. (2017). The conceptual complexity of vocabulary in elementary-grades core science program textbooks. Reading Research Quarterly, 52(4), 417-442. doi: 10.1002/rrq.184

Gödek, Y., Polat, D. ve Kaya, V. H. (2018). Fen bilgisi öğretiminde kavram yanılgzları Kavram yanılgilarmm tespiti-giderilmesi ve uygulamal örnekler. Ankara: Pegem Akademi.

Green, S. ve Smith III, J. (2005). Small things draw biginterest. Science and Children, $42(4), 30-34$.

Güldal, C. G. (2018). Modellemeye dayal fen öğretiminin ortaokul öğrencilerinin fen kavramların günlük yaşamla ilişkilendirmelerine ve fen kaygllarına etkisi.Yayımlanmamış yüksek lisans tezi. Akdeniz Üniversitesi, Antalya.

Güneş, F. (2007). Türkçe öğretimi ve zihinsel yapılandırma. Ankara: Nobel.

Halloun, I. (2006). Modeling theory in science education. Netherlands: Springer.

Halloun, I. (2007). Mediated modeling in science education. Science \& Education, 16(7), 653-697. doi:10.1007/s11191-006-9004-3

Harman, G. (2012). Analyze the prospective elementary teachers' information's about laboratory equipments that are used in science and technology teaching. Journal of Educational and Instructional Studies in the World,2(1),122-127. 
Heimlich, J. E. ve Pittelman, S. D. (1986). Semantic mapping: Classroom applications. Newark, DE: IRA Publications.

Hofstein, A. ve Lunetta, V. N. (1980). The role of the laboratory in science teaching: Research Implications. Sözlü bildiri, The Annual Meeting of the National Association for Research in Science Teaching, Nisan 11-13, Boston.

İnel-Ekici, D. (2014). Kavram öğretimi. Şengül S. Anagün ve Nil Duban (Ed.), Fen bilimleri öğretimi içinde (s. 381-413). Ankara: Anı.

Johnson, A. P. (2015). Eylem araştırması el kitabı (2. baskı). [A short guide to action research.] (Çev. Edt. Y. Uzuner ve M. Özten-Anay) Ankara: Anı. (Orijinal yayın tarihi, 2012)

Kaptan, F. (1998). Fen öğretiminde kavram haritası yönteminin kullanılması. Hacettepe Üniversitesi Ĕ̆itim Fakültesi Dergisi, 14(14), 95-99.

Kapuscinski, B. (1981). The purpose of laboratory instruction in high school chemistry: A historical overview. Journal of Chemical Education, 58(2), 194-197.

Kara, Y. (2018). Determining the effects of microscope simulation on achievement, ability, reports, and opinions about microscope in general biology laboratory course. Universal Journal of Educational Research, 6(9), 1981-1990. doi: 10.13189/ujer.2018.060917

Kesercioğlu, T., Balım, A. G., Öztürk, İ. ve Çavaş, B. (2004). Biyoloji uygulamalartI. İzmir: Gema Gelişim Basım.

Ketelhut, D. J., Nelson, B. C., Clarke, J. ve Dede, C. (2010). A multi-uservirtualenvironment for building higher orderin quiry skills in science. British Journal of Educational Technology, 41(1), 56-68.

Köksal, O. ve Atalay, B. (2016). Öğretim ilke ve yöntemleri çağdaş uygulamalarla yöntem ve teknikler. Konya: Eğitim.

Lipson, M. (1995). The effect of semantic mapping instruction on prose comprehension of below-level college readers. Reading Research and Instruction, 34(4), 367-378. doi:10.1080/19388079509558192

McCoy, K. M., Maag, J. W. ve Rucker, S. (1989). Semantic mapping as a communication tool in classrooms for the seriously emotionally handicapped. Behavioral Disorders, 14(4), 226-235.

McIntosh, A. (1995). Conceptual teaching + semantic mapping = discovering connections. Perspectives in Education and Deafness, 14(1), 11-17.

Merraim, S. B. (2013). Nitel araştırma desen ve uygulama için bir rehber. Ankara: Nobel.

Novak, J. D. ve Gowin, D. B. (1984). Learning how to learn. New York: Cambridge University Press. 
Onan, B. (2012). Türkçenin ana dili olarak öğretiminde bilgi işleme süreci. Mersin Üniversitesi Eğitim Fakültesi Dergisi, 8(1), 96-113.

Panichas, M. A. (2006). Formative evaluation of traditional instruction and cooperative inquiry projects in undergraduate chemistry laboratory courses (Yayımlanmamiş doktora tezi). Boston College, United States, Massachusetts.

Patrizi, C., Ice, P. ve Burgess, M. (2013). Semantic mapping of learning assets to align curriculum and evidence learning effectiveness in business education. Business Education \& Accreditation, 5(1), 117-228.

Peşman, H. ve Bülbül, M. Ş. (2012). Postmodern bir drama uygulaması: mekanik kavramları kullanılarak hazırlanmış kavram ağı. e-Journal of New World Sciences Academy, 7(1), 453-458.

Reza, N. A. \& Azizah, N. A. (2019). Semantic mapping strategy on students' vocabulary learning result. Lingua Jurnal Pendidikan Bahasa, 15(2), 27-34. doi:10.34005/lingua.v15i2.357

Sadeghi, K. ve Taghavi, E. (2014). The relationship between semantic mapping instruction, reading comprehension and recall of Iranian undergraduates reading English texts. Mextesol Journal, 38(1), 1-13.

Saragih, E. (2019). The effect of semantic mapping technique on technical vocabulary mastery for midwifery students. Studies in English Language and Education, 6(2), 333-342. doi:10.24815/siele.v6i2.14786

Schewel, R. (1989). Semantic mapping: A study skills strategy. Academic Therapy, 24(4), 439-447. doi:10.1177/105345128902400407

Senemoğlu, N. (2018). Gelişim, öğrenme ve öğretim-Kuramdan uygulamaya (26. baskı). Ankara: Anı.

Switzer, P. V. ve Shriner, W. M. (2000). Mimicking the scientific process in the upper-division laboratory. Bioscience, 50(2), 157-162. doi:10.1641/00063568(2000)050[0157:mtspit]2.3.co;2

Taşkın,Ö.(2008).Fen ve Teknoloji öğretiminde yeni yaklaşımlar.Ankara:Pegem Akademi.

Tuna, F. (2013). Ortaöğretim coğrafya öğretiminde kavram ağı yönteminin öğrencilerin başarısına etkisi ve öğrencilerin yöntem hakkındaki görüşleri. Kastamonu Ĕ̆itim Dergisi, 21(3), 985-996.

Türk Dil Kurumu [TDK] (2019). Türk dil kurumu sözlükleri. Erişim adresi https://sozluk.gov.tr/ 
Uzel, N., Diken, E. H., Yılmaz, M. ve Gül, A. (2011). The problems that science and technology and biology student teachers face in the use of microscopes and determining the causes of these problems. 2nd International Conference on New Trends in Education and Their Implications, Nisan 27-29, Antalya-Türkiye.

Vaughan, M. N., Sumrall, J. ve Rose, L. H. (1998). Preservice teachers use the newspaper to teach science and social studies literacy. Journal of Elementary Science Education, 10(2), 1-19. doi:10.1007/bf03173781

Washington, V. M. (1988). Report writing: A practical application of semantic $\begin{array}{llll}\text { mapping. } & \text { 24-30. }\end{array}$ doi:10.1080/08878738809554930

Yazıc1, M. ve Kurt, A. (2018). Ortaokul fen bilimleri dersinde laboratuvar kullanımının öğretmen ve öğrenci görüşleri doğrultusunda incelenmesi. Bayburt Ĕ̆itim Fakültesi Dergisi, 13(25), 295-320.

Yılmaz, K. ve Çiviler, M. (2012). İlköğretim 6. sınıf sosyal bilgiler dersi “Yeryüzünde Yaşam" ünitesinde yer alan tarih kavramlarının öğretiminde karşılaşılan kavram yanılgıları üzerine bir eylem araştırması. Türk Tarih Ĕğitimi Dergisi, 1(1), 1-31.

Zorlu, F. (2016). Fen Bilimleri dersinin öğretiminde Solomon araştırma deseninin işbirlikli öğrenme modeline uygulanmasının etkililiğinin incelenmesi.Yayımlanmamış doktora tezi. Atatürk Üniversitesi, Erzurum.

Zorlu, F. ve Sezek, F. (2019). Students' opinions about the effect of the application of learning together and group investigation methods at different intervals on the features of cooperative learning model. Malaysian Online Journal of Educational Sciences, 7(2), 10-24.

\section{Kaynakça Bilgisi / Citation Information}

Zorlu, F. ve Zorlu, Y. (2020). Fen bilgisi öğretmen adaylarının mikroskop konusuna yönelik kavramları öğrenmelerinin geliştirilmesi. OPUS-Uluslararası Toplum Araştırmaları Dergisi, 15(25), 3582-3600. DOI: 10.26466/opus.647849 